\title{
Expression of endoglucanases in Pichia pastoris under control of the GAP promoter
}

\author{
Anikó Várnai ${ }^{*}$, Campbell Tang ${ }^{2}$, Oskar Bengtsson ${ }^{1}$, Andrew Atterton² ${ }^{2}$ Geir Mathiesen ${ }^{1}$ and Vincent GH Eijsink ${ }^{1}$
}

\begin{abstract}
Background: Plant-derived biomass is a potential alternative to fossil feedstocks for a greener economy. Enzymatic saccharification of biomass has been studied extensively and endoglucanases have been found to be a prerequisite for quick initial liquefaction of biomass under industrial conditions. Pichia pastoris, widely used for heterologous protein expression, can be utilized for fungal endoglucanase production. The recently marketed PichiaPink ${ }^{\mathrm{TM}}$ expression system allows for rapid clone selection, and employs the methanol inducible AOX1 promoter to ensure high protein expression levels. However, methanol is toxic and poses a fire hazard, issues which become more significant at an industrial scale. It is possible to eliminate these risks and still maintain high productivity by switching to the constitutive GAP promoter.

Results: In the present study, a plasmid carrying the constitutive GAP promoter was created for PichiaPink ${ }^{\mathrm{TM}}$. We then studied expression of two endoglucanases, AfCel12A from Aspergillus fumigatus and TaCel5A from Thermoascus aurantiacus, regulated by either the AOX1 promoter or the GAP promoter. Initial experiments in tubes and small bioreactors showed that the levels of AfCel12A obtained with the constitutive promoter were similar or higher, compared to the AOX1 promoter, whereas the levels of TaCel5A were somewhat lower. After optimization of cultivation conditions using a $15-$ I bioreactor, the recombinant $P$. pastoris strains utilizing the GAP promoter produced ca. 3-5 g/l of total secreted protein, with CMCase activity equivalent to $1200 \mathrm{nkat} / \mathrm{ml}$ AfCel12A and $170 \mathrm{nkat} / \mathrm{ml}$ TaCel5A.

Conclusions: We present a strategy for constitutive recombinant protein expression in the novel PichiaPink ${ }^{\mathrm{TM}}$ system. Both AfCel12A and TaCel5A were successfully expressed constitutively in P. pastoris under the GAP promoter. Reasonable protein levels were reached after optimizing cultivation conditions.
\end{abstract}

Keywords: Endoglucanase, Heterologous protein expression, Pichia pastoris, PichiaPink, AOX1 promoter, GAP promoter

\section{Background}

Conversion of lignocellulosic biomass to energy and/or value added products provides an attractive alternative to today's petrol-based production of chemicals and transportation fuels [1]. Saccharification of cellulose may be attained enzymatically using endoglucanases, cellobiohydrolases, lytic polysaccharide monooxygenases and $\beta$-glucosidase [2,3]. Endoglucanases (EGs) play a major role in this process, in particular in the initial liquefaction phase [4]. Production and utilization of EGs is therefore crucial for efficient biomass conversion.

The yeasts Pichia pastoris and Saccharomyces cerevisiae are frequently used hosts for heterologous production of

\footnotetext{
* Correspondence: aniko.varnai@nmbu.no

'Department of Chemistry, Biotechnology and Food Science, Norwegian University of Life Sciences, PO Box 5003Chr. Magnus Falsens vei 1, N-1432 Ås, Norway

Full list of author information is available at the end of the article
}

eukaryotic proteins such as fungal biomass-degrading enzymes, mostly because of their relatively high growth rate and good productivity on inexpensive simple media [5]. In addition, yeasts are capable of necessary post-translational modifications such as glycosylation and formation of disulphide bonds. In P. pastoris, glycosylation of proteins is less extensive than in S. cerevisiae [6], which makes $P$. pastoris potentially more suitable for production of heterologous enzymes. Like $S$. cerevisiae, $P$. pastoris is able to secrete proteins, which simplifies subsequent enzyme purification processes. $P$. pastoris is known to secrete low levels of native proteins, none of which has been reported to be active on lignocellulosic biomass $[7,8]$. Only one intracellular $\beta$-glucosidase, an enzyme capable of monomerizing cellooligosaccharides solubilized from lignocellulosic biomass by EGs, has been identified and characterized in P. pastoris [9]. Hence, P. pastoris appears as a favorable 
candidate for the production of individual lignocellulosedegrading enzymes.

Over the last thirty years several promoters have been utilized for heterologous protein production in P. pastoris, but to date only the regulated alcohol oxidase I (AOX1) and the constitutive glyceraldehyde-3-phosphate dehydrogenase (GAP) promoters are used regularly [10-12]. The AOX1 promoter controls expression of the alcohol oxidase (AOX) in the methanol-utilization pathway. The AOX1 promoter is tightly regulated; it is repressed by glucose, glycerol and ethanol, and strongly induced by methanol [13]. The GAP promoter is constitutive, although the strength of expression varies depending on the carbon source [14]. Whilst the advantage of using the AOX1 promoter is that it allows controlled expression of heterologous proteins that may be toxic to the host, the GAP promoter simplifies cultivation by avoiding the need for toxic methanol as a carbon source.

Recently, a novel P. pastoris production strain PichiaPink $^{\text {tum }}$ has been marketed by Invitrogen (Life Technologies Corporation AS, CA, USA). PichiaPink ${ }^{\mathrm{m}}$ is an adenine auxotrophic strain with a precise single gene deletion in the $A D E 2$ gene ( $\triangle a d e 2)$. The absence of the $A D E 2$ gene leads to the accumulation of a red metabolic intermediate, phosphoribosylaminoimidazole, giving a dark pink color to the cells [15]. Transformation of $P$. pastoris ade $2 \mathrm{mu}-$ tant cells with the pPink-HC vector re-introduces the knocked-out gene (ADE2) into the P. pastoris chromosome. Re-establishing the adenine biosynthetic pathway reverts the pink cell color to wild-type white, allowing visual selection of transformants [16].

In the present work, the PichiaPink ${ }^{\text {Tw }}$ expression system was selected for expression of two fungal endoglucanases (EGs), Thermoascus aurantiacus TaCel5A and Aspergillus fumigatus AfCel12A. Plasmids carrying either the AOX1 promoter or the GAP promoter were constructed for both EGs and transformed into the double protease knock-out PichiaPink ${ }^{\text {tw }}$ Strain 4 . The resulting four recombinant $P$. pastoris strains were cultivated in tubes, shake flasks and bioreactors, and EG yields were compared. Finally, cultivation conditions for the bestperforming recombinant $P$. pastoris strains, with the GAP promoter, were optimized for enzyme production at bioreactor scale.

\section{Results and discussion}

\section{Constructing the pPink-GAP expression vectors}

In the present study, we selected two EGs from different glycoside hydrolase (GH) families for expression in P. pastoris: a GH family 12 EG, AfCel12A from Aspergillus fumigatus [UniProt:Q4WGT4], and a GH family 5 EG, TaCel5A from Thermoascus aurantiacus [UniProt:Q8TG26].
In all constructs, secretion of the enzymes was driven by the native secretion signals.

Synthetic genes encoding the two EGs were inserted downstream of the inducible AOX1 promoter into the commercially available pPink- $\mathrm{HC}$ vector, yielding plasmids pPink_AfCel12A and pPink_TaCel5A (Additional file 1: Figure S1). No PichiaPink ${ }^{\mathrm{Tw}}$ expression vectors were available for constitutive expression of recombinant proteins. The AOX1 promoter in pPink-HC was therefore replaced with the GAP promoter and one of the two EG genes was then inserted, creating a third construct, pPink-GAP_AfCel12A (Additional file 1: Figure S1). The Kozak-sequence from the native AOX1 gene of P. pastoris "GAAACG" was inserted in front of the start codon to ensure efficient translation initialization [17]. A fourth construct, pPink-GAP_TaCel5A, was made by replacing the sequence encoding $A f C e l 12 \mathrm{~A}$ with that encoding $T a C e l 5 \mathrm{~A}$. The constructed plasmids were transformed into the double protease knock-out PichiaPink ${ }^{\text {Tw }}$ Strain 4 and integrated into the yeast chromosome, giving four recombinant $P$. pastoris strains: AOX1/AfCel12A, AOX1/TaCel5A, GAP/AfCel12A and GAP/TaCel5A.

\section{Screening and selection of transformants}

Three to five white colonies from each transformation were selected for initial screening. With the exception of one clone, GAP/TaCel5A clone 2, all clones formed uniformly white colonies after being re-streaked on fresh PAD selection plates. The GAP/TaCel5A clone 2 transformant gave sectored (both white and pink) colonies, which indicate unstable integration of the vector into the $P$. pastoris genome [16]. For most of the tested clones, both enzymes were successfully produced and secreted, and enzymatic activity could be detected in culture supernatants (Figure 1 and Additional file 1: Figure S2). The GAP/AfCel12A clone 2 did not produce detectable amounts of enzyme, formed colonies with different morphology, and grew poorly on YPD medium as compared to $P$. pastoris. This clone was probably a contaminating strain able to grow due to the lack of antibiotics in the medium and was excluded from further work.

Heterologous expression in both $P$. pastoris and S. cerevisiae may lead to hyperglycosylation, which is attributed primarily to $\mathrm{N}$-glycosylation [18]. Glycosylation may lead to the recombinant proteins appearing at unexpected positions in SDS-PAGE gels (1-2 kDa shift per glycosylation), whereas heterogeneous hyperglycosylation may yield proteins appearing as smears [18]. To assess $\mathrm{N}$-glycosylation, one clone of each transformant was selected and the proteins in the cell-free culture supernatants were subjected to EndoH treatment. Protein bands appeared on the SDS-PAGE gel of the cell-free supernatants at the expected molecular weights, $24 \mathrm{kDa}$ for AfCel12A and $37 \mathrm{kDa}$ for TaCel5A (Additional file 1 : 

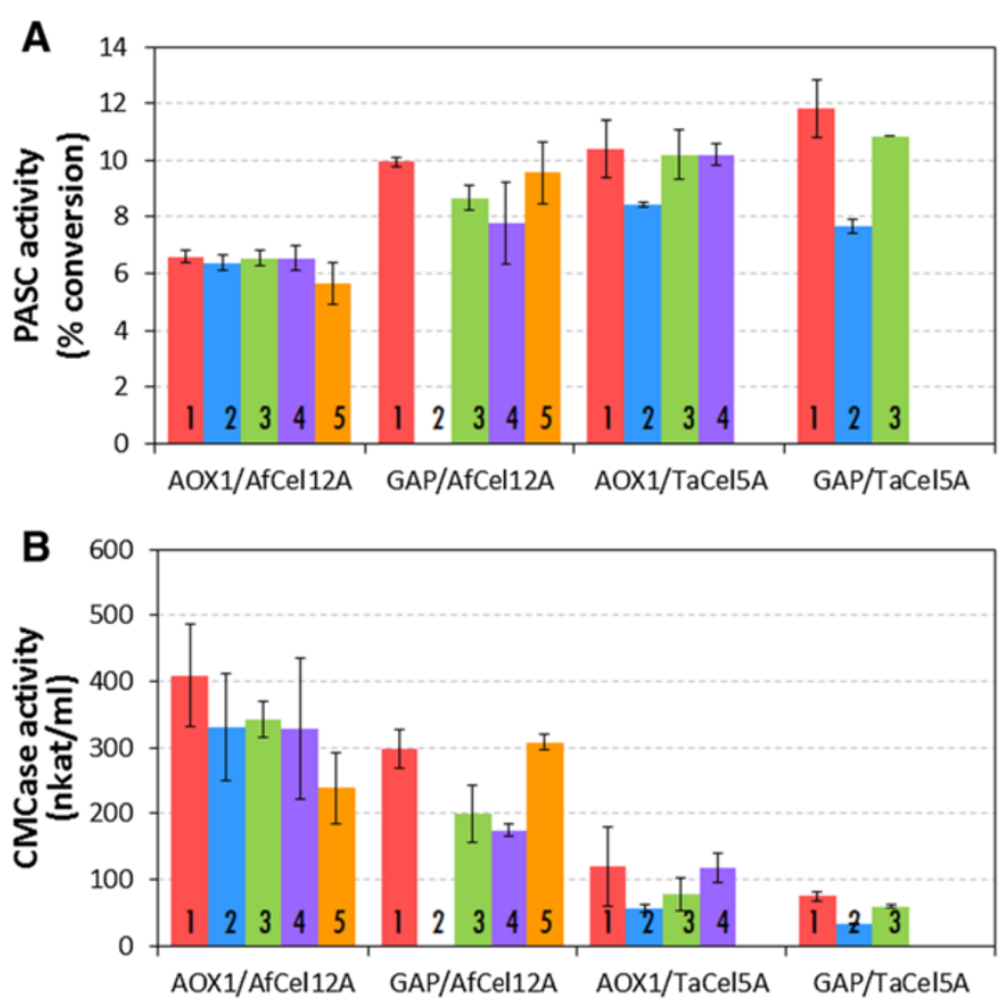

Figure 1 Endoglucanase activity in culture supernatants obtained during tube-scale screening of transformants. Culture supernatants were collected from the AOX1 strains 48 hours after induction, and from the GAP strains after 48 hours of incubation (see Methods for more details). A) Endoglucanase activity was measured on filter paper by incubating $10 \mu \mathrm{l}$ culture supernatant with $40 \mu \mathrm{l}$ of a suspension of phosphoric acid swollen filter paper ( $1 \% \mathrm{w} / \mathrm{v}$ ) and $10 \mu \mathrm{l} 50 \mathrm{mM}$ Na-citrate buffer ( $\mathrm{pH} \mathrm{5.0)}$ for 1 hour at $50^{\circ} \mathrm{C}$. B) Endoglucanase activity was measured on carboxymethylcellulose by incubating $50 \mu$ lappropriately diluted culture supernatant with $450 \mu \mathrm{l}$ \% (W/v) carboxymethylcellulose in $50 \mathrm{mM}$ Na-citrate buffer (pH 5.0) for $10 \mathrm{~min}$ at $50^{\circ} \mathrm{C}$. Enzyme activities were assessed by measuring formation of reducing sugars. Filter paper activity is expressed as percentage of substrate conversion; CMCase activity is expressed as nkat/ml. The activity values were background corrected by measuring reducing sugars

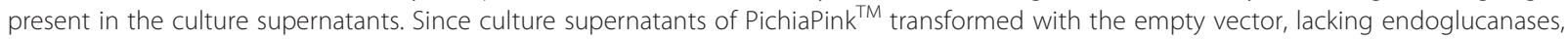
showed no activity, all activity can be attributed to the recombinant endoglucanases. The data are means from triplicate experiments; error bars reflect standard deviations. The clone number is indicated in the bars.

Figure S2), indicating that the proteins were processed correctly. The EndoH treatment did not change the apparent molecular weight of the secreted EGs, confirming that the enzymes were produced without excessive $\mathrm{N}$-glycosylation (Additional file 1: Figure S3), which is in agreement with both enzymes having a limited number of putative $\mathrm{N}$-glycosylation sites.

EG activity was measured in supernatants from the recombinant $P$. pastoris clones using a cellulosic model substrate (Phosphoric Acid Swollen Cellulose from Filter Paper, Whatman No. 1, PASC-FP) or carboxymethylcellulose $(\mathrm{CMC})$, a water-soluble cellulose derivative. Supernatants from all checked clones exhibited activity on PASC-FP and CMC (Figure 1; note that the activity levels on $\mathrm{CMC}$ seem proportional to band intensities in Additional file 1: Figure S2; this is not the case for the activities on PASC-FP due to the non-linearity of the PASC-FP assay). Figure 1 shows that enzyme levels produced with the GAP and AOX1 promoters are similar, with some variations that are explored further below. A control strain transformed with the vector pPink-HC showed no endoglucanase activity on PASC-FP, confirming that the activity in the supernatants of the production strains was due to secreted recombinant EG.

Two clones from each transformation (with the highest activity in Figure 1) were evaluated in shake flask cultures. Generally, enzyme activity reached levels similar to those observed during the tube scale screening, confirming that EG activity varies slightly with the promoter used. The activity of both enzymes reached higher levels on PASC-FP when expressed under the constitutive GAP promoter than under the AOX1 promoter, in particular for $A f C e l 12 \mathrm{~A}$, which is in accordance with Figure 1A.

\section{Fed-batch cultivation in bioreactors}

To reach reasonable production of the endoglucanases, clones giving the highest enzyme titers were selected for each transformant, namely: AOX1/AfCel12A clone 1, GAP/ AfCel12A clone 1 , AOX1/TaCel5A clone 1 and GAP/ TaCel5A clone 1 . Firstly, these clones were cultivated in 
a 3-1 bioreactor using fed-batch cultivation (1 1 initial volume in batch phase) following the protocol described by Stratton et al. [19] without optimizing parameters of cultivation. The levels of secreted total proteins varied between $1-5 \mathrm{~g} / \mathrm{l}$, which is common for the production of lignocellulolytic enzymes in yeast in fed-batch cultivations [20]. Enzyme expression, monitored with SDS-PAGE (Figure 2), was clearly higher than that in the tube-scale cultures used in the initial screening phase (Additional file 1: Figure S2). Accordingly, the endoglucanase activity in the supernatants obtained from the bioreactors amounted to 10.0\% (AOX1/ AfCel12A), 11.7\% (GAP/AfCel12A), 13.6\% (AOX1/TaCel5A) and $14.2 \%$ of conversion (GAP/TaCel5A) of PASC-FP in the filter paper assay, and to $630 \mathrm{nkat} / \mathrm{ml}$ (AOX1/AfCel12A), $1200 \mathrm{nkat} / \mathrm{ml}$ (GAP/AfCel12A), $290 \mathrm{nkat} / \mathrm{ml}$ (AOX1/ TaCel5A) and $190 \mathrm{nkat} / \mathrm{ml}$ (GAP/TaCel5A) on CMC, which are values higher than those obtained in the initial screening experiments (Figure 1). Whilst AfCel12A appeared as the major band on the gel, with the GAP promoter working better, bands representing TaCel5A were less prominent and in this case the AOX1 promoter worked slightly better (Figure 2).

AfCel12A and TaCel5A were purified from a culture supernatant and their specific activities on $\mathrm{CMC}$ were determined to be 1040 and 1450 nkat/mg, respectively. Comparing these values with specific activities measured for culture supernatants of the GAP promoter indicated that AfCel12A amounted to approximately 35\% of total protein in the best supernatants shown in Figure 2, whereas this value was approximately $5 \%$ for TaCel5A. The ratio of endoglucanase to background proteins was higher in case of methanol-induced expression, AfCel12A and TaCel5A making up approximately $60 \%$ and $25 \%$ of total secreted protein, respectively. Thus, in terms of the amount of EG protein produced, production of AfCel12A was more successful, similar to what was observed in the experiments with tubes and shake flasks.

Fermentation development in 15-1 stainless steel steamin-place fermenters was carried out only for the GAP strains expressing AfCel12A and TaCel5A, since the screening and initial fermentation experiments consistently indicated that the GAP promoter worked better than (AfCel12A) or approximately as well as $(\operatorname{TaCel} 5 \mathrm{~A})$ the AOX1 promoter. Fermentation development in such fermenters facilitates straightforward upscaling to pilot plant scale production and beyond. Cultivation conditions were optimized with particular focus on temperature, carbon source and feeding regime. Initially, both glycerol and glucose were evaluated, and feeding regimes were set based on the fermentation guidelines by Stratton et al. [19].

Firstly, the effect of increasing the glycerol feed rate was tested. Increasing the feed from $1714 \mathrm{~g}$ to $2470 \mathrm{~g}$ over 70 hours resulted in increased biomass and total secreted protein with both the GAP/TaCel5A and GAP/ AfCel12A strains, as would be expected from the extra carbon availability (Table 1 ). The overall secreted protein almost doubled with the feed increase (from 2.8 to $3.8 \mathrm{~g} / \mathrm{l}$ ) for the TaCel5A expressing strain, whereas no significant increase was observed (from 3.4 to $3.3 \mathrm{~g} / \mathrm{l}$ ) for the strain expressing AfCel12A. However, there was a marked difference between the strains in terms of enhanced endoglucanase productivity as judged by band intensities on the SDS-PAGE gels. Whilst increased glycerol feed led to no improvement of the TaCel5A yield, there was a significant increase in AfCel12A yield as well as in its proportion relative to other secreted proteins (Additional file 1: Figure S4).

Secondly, glycerol and glucose were compared as the carbon source in the fed-batch phase. For both strains,
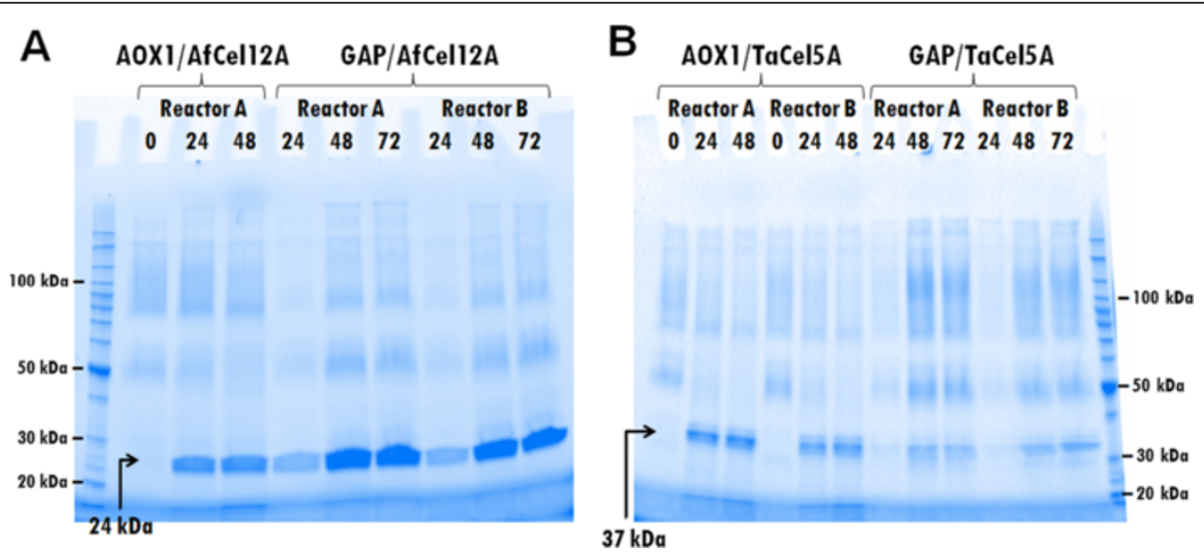

Figure 2 Endoglucanase production in 3-liter bioreactors with fed-batch cultivation. One clone of each PichiaPink ${ }^{\mathrm{TM}}$ recombinant strain was grown in two parallel 3-I fermenters. The SDS-PAGE figures show the accumulation of A) AfCel12A and B) TaCel5A. Sample lanes are marked with the age of the culture in hours for each fermenter. Reactor B of AOX1/AfCel12A is missing from the gel as cells stopped growing in the batch phase. The bands appearing at approx. $24 \mathrm{kDa}$ (panel A) represent AfCel12A; the bands appearing at approx. $37 \mathrm{kDa}$ represent TaCel5A (panel B). 


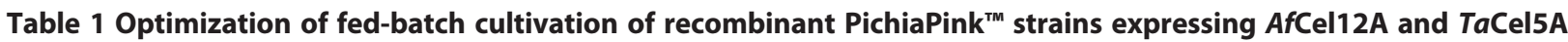
endoglucanases

\begin{tabular}{lllllll}
\hline Run & Strain & Temperature $\left({ }^{\circ} \mathrm{C}\right)$ & Feed & Feed regime & Max dry cell weight (g/l) & Total supernatant protein $(\mathbf{g} / \mathbf{l})$ \\
\hline 1 & GAP/TaCel5A & 30 & Glycerol & $1714 \mathrm{~g}$ over $70 \mathrm{~h}$ & 109 & 2.8 \\
$2^{\mathrm{b}}$ & GAP/TaCel5A & 30 & Glycerol & $2470 \mathrm{~g}$ over $70 \mathrm{~h}$ & $155 \pm 5$ & $3.8 \pm 0.4$ \\
3 & GAP/TaCel5A & 30 & Glucose & $2470 \mathrm{~g}$ over $70 \mathrm{~h}$ & 145 & 4.9 \\
4 & GAP/TaCel5A & 25 & Glycerol & $2470 \mathrm{~g}$ over $70 \mathrm{~h}$ & 155 & 5.4 \\
5 & GAP/AfCel12A & 30 & Glycerol & $1714 \mathrm{~g}$ over $70 \mathrm{~h}$ & 132 & 3.4 \\
$6^{\mathrm{b}}$ & GAP/AfCel12A & 30 & Glycerol & $2470 \mathrm{~g}$ over $70 \mathrm{~h}$ & $146 \pm 9$ & $3.3 \pm 0.3$ \\
7 & GAP/AfCel12A & 30 & Glucose & $2470 \mathrm{~g}$ over $70 \mathrm{~h}$ & 100 & n.d. $^{\text {a }}$ \\
8 & GAP/AfCel12A & 25 & Glycerol & $2470 \mathrm{~g}$ over $70 \mathrm{~h}$ & 170 & 7.3 \\
\hline
\end{tabular}

${ }^{\mathrm{a}}$ Not determined; ${ }^{\mathrm{b}}$ Optimal parameters, fermentations run in 5 parallels.

Fermentations were carried out to analyze the effect of temperature, increased glycerol feed and carbon source on the GAP/TaCel5A strain and the GAP/AfCel12A strain. The PichiaPink ${ }^{T M}$ cells were grown in 15-I scale bioreactors with a 5 -I initial volume for 24 hours in batch mode, followed by feeding as indicated; see Methods for more details. Runs were performed as single experiments; however, optimized runs were performed five times, and standard deviations are provided. SDS-PAGE analyses of the culture supernatants are shown in Figure 3.

glycerol appeared to be a better carbon source than glucose, resulting in higher biomass concentrations, and higher endoglucanase yields (Table 1 and Figure 3). Additionally, the glycerol feed resulted in faster AfCel12A production, with maximum levels being reached earlier during the fermentation (compare Figure 3B and D). Previous studies on comparing glucose and glycerol in GAP-driven expression have given varying results. For example, glycerol gave better yields for human angiostatin [21] and a phytase [22], whilst glucose gave better yields in other cases [14,23]. The choice of carbon source thus appears to depend on the individual gene. Our results indicate that glycerol would be a better carbon source to use in the case of $T a C e l 5 \mathrm{~A}$ and AfCel12A.

Thirdly, the effect of lowering the temperature on growth and enzyme production was evaluated. Decreasing the cultivation temperature from $30^{\circ} \mathrm{C}$ to $25^{\circ} \mathrm{C}$ hardly affected growth and supernatant protein concentrations for the TaCel5A clone (Table 1 and Figure 3) but the SDS-PAGE analyses indicated slightly higher relative yields of $\mathrm{TaCel} 5 \mathrm{~A}$ at $30^{\circ} \mathrm{C}$ (Figure $3 \mathrm{~A}$ and $\mathrm{E}$ ). On the other hand, total secreted protein by $P$. pastoris expressing AfCel12A was considerably higher at $25^{\circ} \mathrm{C}(7.3 \mathrm{~g} / \mathrm{l}$ at $25^{\circ} \mathrm{C}$ compared to $3.8 \mathrm{~g} / \mathrm{l}$ at $30^{\circ} \mathrm{C}$ ) (Table 1 ). The SDSPAGE analyses (Figure $3 \mathrm{~B}$ and $\mathrm{F}$ ) show that maximum AfCel12A levels were similar at both temperatures and clearly show that the EG produced at $30^{\circ} \mathrm{C}$ contained much less contaminating proteins.

All in all, under optimized conditions we were able to reach protein concentrations in the supernatants in the range of $5 \mathrm{~g} / \mathrm{l}$. CMCase activity in the supernatants of the optimized cultures (grown on glycerol at $30^{\circ} \mathrm{C}$ ) amounted to $1200 \pm 100 \mathrm{nkat} / \mathrm{ml}$ (GAP/AfCel12A) and $170 \pm 10$ (GAP/TaCel5A), representing a two- to three-fold increase compared to the shake flask cultivations. Figure 3 (panels $\mathrm{A}$ and $\mathrm{B}$ ) shows that under these optimized conditions, recombinant AfCel12A is the major extracellular protein, whereas $\mathrm{TaCel} 5 \mathrm{~A}$ is produced at considerably lower levels.
By comparing the specific CMCase activity in the culture supernatants to the specific CMCase activity of the purified EGs, AfCel12A was estimated to represent $36 \%$ of total secreted protein, whereas this value was $4 \%$ for TaCel5A.

As to comparing the GAP and AOX1 promoters, the data show that the overall efficiency of protein expression under the regulation of AOX1 or GAP promoters in $P$. pastoris depends on the protein that is expressed. This is also reflected in existing literature data [12]. In several cases, the GAP promoter was found to be superior to the AOX1 promoter [14,24], whereas in other cases the picture was less clear [20].

As far as the downstream processing is concerned, recombinant endoglucanase preparations may not need to be purified prior to their application in biomass valorization for a number of reasons. Other secreted proteins may act as surfactants and reduce non-productive binding of cellulases [25]. In addition, as the currently used PichiaPink ${ }^{\text {тM }}$ strain 4 is double protease deficient, proteolysis of the endoglucanase is unlikely. In industrial applications, where processes are lengthier than in the laboratory, this is important as it would prolong the durability of the EGs. Furthermore, P. pastoris strains, in general, produce no lignocellulolytic enzymes $[7,8]$. Some intracellular $\beta$-glucosidase [9] may be released to the cell-free culture broth as a result of cell lysis, but this would rather enhance than retard lignocellulose hydrolysis. Hence, $P$. pastoris appears as a favorable candidate for production of endoglucanases and other lignocellulose-degrading enzymes.

\section{Conclusions}

We have constructed a plasmid (pPink-GAP) for constitutive expression of recombinant proteins with the PichiaPink $^{\mathrm{TM}}$ system in order to simplify enzyme production compared to methanol inducible expression systems. Two endoglucanases, AfCel12A from Aspergillus fumigatus and 


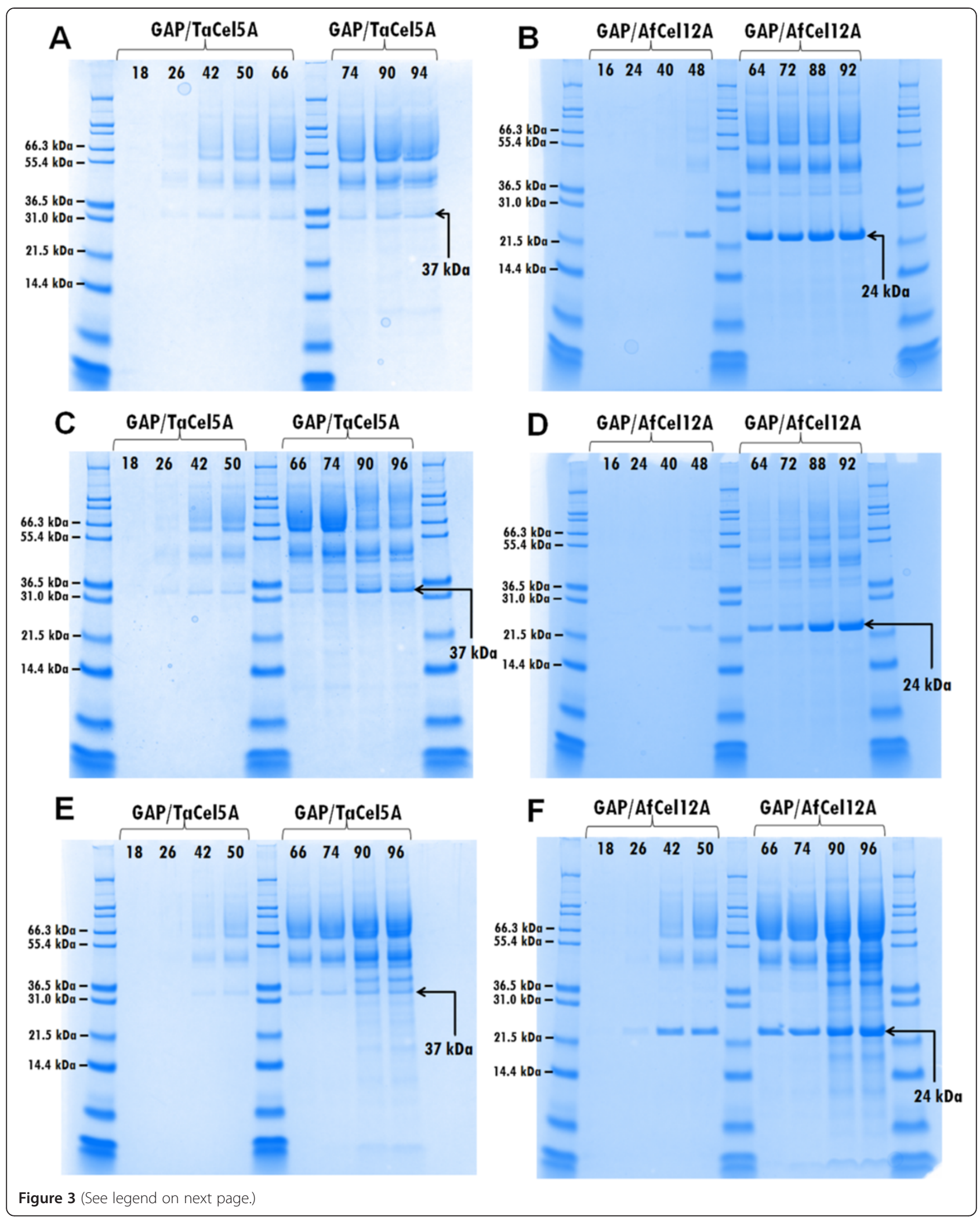


(See figure on previous page.)

Figure 3 Optimization of fed-batch cultivations for production of TaCel5A and AfCel12A. Fed-batch cultivations for producing TaCel5A $(\mathbf{A}, \mathbf{C}, \mathbf{E})$ and AfCel12A (B, D, F) were performed in glycerol at $30^{\circ} \mathrm{C}(\mathbf{A}, \mathbf{B})$, in glucose at $30^{\circ} \mathrm{C}(\mathbf{C}, \mathbf{D})$ and in glycerol at $25^{\circ} \mathrm{C}(\mathbf{E}, \mathbf{F})$. Carbon sources were introduced as a stepped feed of $2470 \mathrm{~g}$ (3.9 I) of glycerol or glucose over $70 \mathrm{~h}$, following a 24-h batch phase, with an initial volume of $5 \mathrm{I}$. Fermentation parameters were controlled at standard settings (see Methods). Culture supernatant samples were collected at various time points and analyzed by SDS-PAGE $(15 \mu \mathrm{l}$ sample size). Sample lanes are marked with the age of the culture in hours. Bands marked as $37 \mathrm{kDa}$ represent TaCel5A. Bands marked as $24 \mathrm{kDa}$ represent AfCel12A. The protein standard was Mark12 Unstained Standard (Invitrogen). Additional data for these fermentations are provided in Table 1.

TaCel5A from Thermoascus aurantiacus, were successfully expressed in PichiaPink ${ }^{\mathrm{TM}}$ under the GAP promoter, and transformants produced up to $5 \mathrm{~g} / \mathrm{l}$ total secreted protein after optimization in bioreactors, with $36 \%$ and $4 \%$ of the total proteins being $A f C e l 12 \mathrm{~A}$ and $T a C e l 5 \mathrm{~A}$, respectively. We found that increasing the glycerol feed resulted in higher endoglucanase yields, that glycerol was more favorable as a carbon source than glucose, and that cultivating transformants at $30^{\circ} \mathrm{C}$ led to a smaller proportion of background proteins relative to the endoglucanase than at $25^{\circ} \mathrm{C}$. Due to the limited number of potential $\mathrm{N}$ glycosylation sites (none and one, respectively), AfCel12A and $\mathrm{TaCel} 5 \mathrm{~A}$ both could be produced without hyperglycosylation, simplifying downstream processing.

\section{Methods}

\section{Bacterial strains and plasmids}

Chemically competent E. coli TOP10 (Invitrogen, Life Technologies Corporation AS, CA, USA) was used as subcloning host for the pPink-HC plasmids. The PichiaPink ${ }^{\text {тм }}$ Secretion Optimization Kit, containing PichiaPink ${ }^{\mathrm{Tm}}$ Strain 4 ( $P$. pastoris ade2, prb1, pep4-adenine auxotroph and double protease knock-out strain), the expression vector pPink-HC and PichiaPink ${ }^{\mathrm{Tm}}$ Media Kit, as well as the pGAPZ $\alpha$ A vector were all purchased from Invitrogen.

The coding regions, including the native signal sequence, of the genes cel12A of Aspergillus fumigatus encoding AfCel12A [GenBank:NC_007200.1 REGION: 1511096..1511900, UniProt:Q4WGT4] and eg1 of Thermoascus aurantiacus encoding TaCel5A [GenBank:AF487830.2, UniProt:Q8TG26] were synthesized by GenScript USA Inc. (NJ, USA) using standard procedures for codon optimization for Pichia expression. The Kozak-sequence from the native AOX1 gene of $P$. pastoris (GAAACG) was inserted before the start codon (Additional file 1: Figure S1D) to enhance translation initiation [17]. All primers were synthesized by Eurofins MWG Synthesis GmbH (Germany) and the sequences of all PCR-amplified DNA fragments were confirmed by GATC Biotech AG (Germany).

\section{Media and chemicals}

E. coli was grown on Brain-Heart-Infusion medium (Lonza, ME, USA) with $100 \mu \mathrm{g} / \mathrm{ml}$ ampicillin (Sigma-Aldrich, Inc, St. Louis, MO). Agar plates were solidified with $1.6 \%$ (w/v) BactoAgar (Saveen Werner AB, Sweden). For P. pastoris, the PichiaPink ${ }^{\mathrm{TM}}$ Media Kit (Invitrogen) including BMGY, BMMY, YPD and YPDS media and YPD and PAD (Pichia adenine dropout) plates was used for cultivation. All chemicals for the medium used in the bioreactors were purchased from Sigma-Aldrich unless otherwise stated.

\section{Plasmid construction and transformation of $\mathrm{P}$. pastoris}

To insert the endoglucanase genes into pPink-HC with the AOX1 promoter, the synthetic cel12A and eg1 genes were excised from the pUC57 vector using Acc65I and EcoRI (both from New England BioLabs [NEB] Inc, MA) and ligated into the same sites of pPink-HC, yielding pPink_AfCel12A and pPink_TaCel5A, respectively (Additional file 1: Figure S1A).

In order to replace the methanol-inducible AOX1 promoter with the constitutive GAP promoter, we first amplified the GAP promoter from the pGAPZ $\alpha$ (Invitrogen) plasmid with primers P1 (CAGTGAATTGAGATCTTTT TTGTAGAAATGTCTTGGTGTCC) and P2 (GTCTTCA TCGTTTCGAATTCCGTTTCGAAATAGTTGTTCAAT TGAT) and the cel12A gene from the pPink_AfCel12A plasmid with primers P3 (CCCTATTTCAATCAATT GAACAACTATTTCGAAACGGAATTCGAAACGAT) and P4 (ATGGCCGGCCGGTAC) using Phusion highfidelity DNA polymerase (NEB); in P2 and P3 the Kozak sequence is indicated in bold and the EcoRI site in italic. These two PCR fragments with 56 overlapping base pairs were fused together in a splicing by overlap extensionPCR (SOE-PCR) reaction [26] using primers P1 and P4 (Additional file 1: Figure S1B). The resulting fragment was subsequently In-Fusion cloned into the BglII/Acc65I fragment of the pPink_AfCel12A, resulting in pPinkGAP_AfCel12A (Additional file 1: Figure S1C). This strategy led to the introduction of an EcoRI site after the GAP promoter (encoded by primer P2), allowing exchange of the target gene. The fourth plasmid was constructed by replacing the synthesized $c e l 12 \mathrm{~A}$ gene in the vector pPinkGAP_AfCel12A with the synthesized eg1 gene using EcoRI and Acc65I, yielding pPink-GAP_TaCel5A.

The four vectors were linearized with $A f l \mathrm{II}(\mathrm{NEB})$ and $3 \mu \mathrm{g}$ of each plasmid were transformed into electrocompetent cells of P. pastoris PichiaPink ${ }^{\mathrm{TM}}$ Strain 4. The Pichia$\operatorname{Pink}^{\mathrm{TM}}$ strain was made electrocompetent by following the manufacturer's instruction [27] and transformed using a Bio-Rad Gene Pulser II electroporation system (Bio-Rad 
Laboratories, CA, USA) at $1.8 \mathrm{kV}, 25 \mu \mathrm{F}, 200 \Omega$, resulting in a time constant of $5 \mathrm{~ms}$. After transformation the cells were incubated in YPDS media overnight and then spread on Pichia adenine dropout (PAD) selection plates (Invitrogen) for $8-12$ days at $30^{\circ} \mathrm{C}$ until colonies formed. Of the colonies, 3-5 white ones were picked and restreaked on fresh PAD plates, glycerol stocks were prepared from overnight cultures in YPD medium in $20 \%$ (v/v) glycerol. Transformants were named based on the promoter/gene combination as $P$. pastoris AOX1/AfCel12A, AOX1/TaCel5A, GAP/AfCel12A and GAP/TaCel5A.

\section{Cultivation of PichiaPink ${ }^{\mathrm{TM}}$ transformants}

Cellulase production by recombinant $P$. pastoris strains was first tested at tube scale. To do so, $10 \mathrm{ml}$ medium was incubated in $50-\mathrm{ml}$ Falcon tubes $\left(30^{\circ} \mathrm{C}\right.$, shaken at $160 \mathrm{rpm}$, at least duplicates). The AOX1 strains (P. pastoris AOX1/ AfCel12A and AOX1/TaCel5A) were grown for 48 hours in BMGY medium (containing 1\% (v/v) glycerol) to increase cell density before induction. After 48 hours the cells were pelleted by centrifugation (1500 g for $5 \mathrm{~min}$ ) and resuspended in $1 \mathrm{ml}$ BMMY medium (containing $0.5 \%(\mathrm{v} / \mathrm{v})$ methanol), and further incubated for 24 hours (the total volume of the culture was approx. $4 \mathrm{ml}$ ). Then a sample of $100 \mu \mathrm{l}$ culture was taken out, $100 \mu \mathrm{l} 40 \%$ (v/v) methanol was added and the cultures were incubated for another 24 hours. Cell-free culture supernatants were harvested by centrifugation (1500 g for $10 \mathrm{~min}$ ) 48 hours after induction and cellulase activity was measured (see below). The PichiaPink $^{\mathrm{Tm}}$ GAP strains (GAP/AfCel12A and GAP/ TaCel5A) were grown for 72 hours in $10 \mathrm{ml}$ YPD medium in $50-\mathrm{ml}$ Falcon tubes at $30^{\circ} \mathrm{C}$ shaken at $160 \mathrm{rpm}, 1 \mathrm{ml}$ sample was collected every 24 hours. Cell growth was determined by measuring the optical density of the cultures at $600 \mathrm{~nm}\left(\mathrm{OD}_{600}\right)$. Samples were centrifuged at $13000 \mathrm{~g}$ for $1 \mathrm{~min}$ and the cell-free supernatants were assayed for cellulase activity.

In the second evaluation, $P$. pastoris transformants were cultivated in $250 \mathrm{ml}$ baffled shake flasks containing $10 \mathrm{ml}$ BMGY (AOX1 strains) or YPD medium (GAP strains) in triplicates, at $30^{\circ} \mathrm{C}$, with shaking at $220 \mathrm{rpm}$. The starting $\mathrm{OD}_{600}$ was set to 0.2 with overnight inoculums grown in YPD medium. The cultivation and sampling were similar to the tube scale experiment (see above) with the exception that PichiaPink ${ }^{\mathrm{TM}}$ clones with AOX1 constructs were grown on BMGY medium for only 24 hours prior to induction. Cell growth and cellulase activity in supernatants were continuously monitored throughout the cultivation.

Next, four P. pastoris clones (AOX1/AfCel12A-1, AOX1/ TaCel5A-1, GAP/AfCel12A-1 and GAP/TaCel5A-1) were cultivated in 3-1 bioreactors (Applikon, The Netherlands) in fed-batch mode according to Stratton et al. [19]. The clones were pre-cultured in $100 \mathrm{ml}$ MGY medium in 1-l baffled shake flasks. One liter basal salts medium supplemented with $2 \mathrm{ml} / \mathrm{l}$ PTM1 trace salt solution [19] was inoculated with $30-50 \mathrm{ml}$ pre-culture, giving a starting $\mathrm{OD}_{600}$ of $1.0-$ 1.5. Cells were grown until depletion of glycerol, then $100 \%$ methanol (AOX1 clones) or $55 \%(\mathrm{w} / \mathrm{v})$ glucose (GAP clones) both containing $0.2 \%$ (v/v) PTM1 solution was fed into the reactors. The methanol feed rate was initially set to $2 \mathrm{ml} / \mathrm{h}$ and was periodically halted to observe dissolved oxygen spikes according to Stratton et al. [19], then slowly increased to $6 \mathrm{ml} / \mathrm{h}$, keeping the dissolved oxygen level at $35 \%$ as suggested by Stratton et al. [19]. The glucose feed rate was $10 \mathrm{ml} / \mathrm{h}$ but was periodically halted until all residual glucose was consumed, leading to variations in the total amount of glucose fed. Samples were taken at regular intervals to follow cell growth and enzyme production; the cultures were harvested after 72 hours of total fermentation time. AOX1/AfCel12A and AOX1/TaCel5A strains were fed in total $130 \mathrm{~g}$ and $280 \mathrm{~g} \mathrm{MeOH}$, respectively; GAP/AfCel12A was fed in total $330 \mathrm{~g}$ (Reactor A) or $280 \mathrm{~g}$ (Reactor B) glucose, and GAP/TaCel5A $250 \mathrm{~g}$ (Reactor A) and $300 \mathrm{~g}$ (Reactor B) glucose.

The GAP clones were selected for further optimization. Fermentations were carried out in 15-1 stainless steel steam-in-place bioreactors (Sartorius Biostat B). Batch phase cultivations were carried out in basal salts medium containing additionally $0.5 \mathrm{ml}$ polypropylene glycol P2000 and $0.025 \mathrm{~g} \mathrm{CuSO}_{4} .5 \mathrm{H}_{2} \mathrm{O}$ per liter [19]. Basal salts medium was supplemented with $4.35 \mathrm{ml} / \mathrm{l}$ PTM1 trace metals solution [27]. Fermenters were set up with $5 \mathrm{l}$ of Basal Salts Medium, and the PTM1 trace metals solution added after sterilization via a $0.2 \mu \mathrm{m}$ sterile filter. Each fermenter was inoculated with $2 \% \mathrm{v} / \mathrm{v}$ of selected $P$. pastoris strain grown for 24 hours (up to $\mathrm{OD}_{600}$ of 15-30) on YPG (40 g/l glycerol, $20 \mathrm{~g} / \mathrm{l}$ soy peptone, $10 \mathrm{~g} / \mathrm{l}$ yeast extract) at $30^{\circ} \mathrm{C}, 220 \mathrm{rpm}$. When carbon limitation (monitored by dissolved oxygen level) became noticeable (after approximately 24 hours), the selected feed strategy was applied. Glycerol and glucose feedstocks consisted of $12 \mathrm{ml} / \mathrm{l}$ PTM1 salt solution with $630 \mathrm{~g} / \mathrm{l}$ glycerol or glucose, respectively. The feeding strategy used is detailed as follows (cumulative feed in bold): $0-24 \mathrm{~h}=0 \mathrm{~g} / \mathrm{h}(\mathbf{0} \mathbf{~ g})$; 24-32 h = $12.6 \mathrm{~g} / \mathrm{h}(\mathbf{1 0 1} \mathbf{g}) ; 32-40 \mathrm{~h}=18.9 \mathrm{~g} / \mathrm{h}(\mathbf{2 5 2} \mathbf{~ g}) ;$ $40-48 \mathrm{~h}=25.2 \mathrm{~g} / \mathrm{h}(\mathbf{4 5 4} \mathbf{g}) ; 48-56 \mathrm{~h}=31.5 \mathrm{~g} / \mathrm{h}(\mathbf{7 0 6} \mathbf{g}) ;$ 56-64 h=37.8 g/h (1008 g); 64-72 h=44.1 g/h (1361 g); 72-94 h=50.4 g/h (2470 g). Unless stated otherwise in the results section, settings for fermentations were $30^{\circ} \mathrm{C}$, pH 5.0 (maintained by $12 \%(\mathrm{w} / \mathrm{w}$ ) ammonium hydroxide). Aeration was set at $5 \mathrm{l} / \mathrm{min}$ (1 vvm) initial flow, with initial agitation at $250 \mathrm{rpm}$, followed by cascading to maintain $30 \%$ dissolved $\mathrm{O}_{2}$. After 24 hours, the airflow was increased to $7.5 \mathrm{l} / \mathrm{min}$ and after 48 hours to $10 \mathrm{l} / \mathrm{min}$, with aeration always cascaded to maintain $30 \%$ dissolved $\mathrm{O}_{2}$. Dry cell weights were determined by centrifuging $10 \mathrm{ml}$ samples, discarding the supernatant, 
and drying the pellet at $70^{\circ} \mathrm{C}$ until a constant weight was obtained.

\section{Analysis of endoglucanase production}

Protein expression was analyzed with SDS-PAGE gel electrophoresis of cell-free supernatants. During selection we used the Mini-Protean TGX Stain Free Gel system (Bio-Rad Laboratories, Inc., CA) with 10\% precast polyacrylamide gels following the manufacturer's instructions; the proteins were visualized with a Bio-Rad Criterion Stain Free Imager system (Bio-Rad Laboratories). During fermentation optimization, SDS-PAGE gel electrophoresis of cell-free supernatants was carried out using the Novex X-Cell II Mini-Cell gel system (Invitrogen) with NuPAGE 10\% Bis-Tris gels (Invitrogen Cat. No. NP0302BOX) and MES SDS Running Buffer (Invitrogen Cat. No. NP0002). Gels were stained with Coomassie Blue.

Protein concentrations were determined using the Bicinchoninic Acid Protein Assay Kit (Cat. No. BCA1$1 \mathrm{KT}$, Sigma-Aldrich). BSA was used for preparation of the standard curve.

Cellulase activity was measured in $60 \mu \mathrm{l}$ reaction mixtures by incubating $10 \mu \mathrm{l}$ cell-free supernatants with phosphoric acid-swollen cellulose from Whatman No 1 filter paper (PASC-FP) at $6.7 \mathrm{~g} / \mathrm{l}$ final substrate concentration in $50 \mathrm{mM} \mathrm{Na}$-citrate buffer $(\mathrm{pH} 5.0)$ at $50^{\circ} \mathrm{C}$ for $60 \mathrm{~min}$. Enzyme activities are expressed as a percentage of the substrate converted, calculated as the ratio of released reducing sugars to the initial substrate concentration, multiplied by a hydrolysis factor of 0.9 . The concentration of reducing sugars was measured using 3,5-dinitrosalicylic acid reagent [28].

The endoglucanase activity was also assayed on carboxymethylcellulose (CMC) as CMCase activity based on the assay by the International Union of Pure and Applied Chemistry [29]. Cell-free supernatants or purified enzyme solutions were diluted to reach the linear range of the assay, then $50 \mu \mathrm{l}$ appropriately diluted enzyme samples were incubated in $500 \mu \mathrm{l}$ reaction mixtures with $\mathrm{CMC}$ at $9 \mathrm{~g} / \mathrm{l}$ final substrate concentration in $50 \mathrm{mM}$ $\mathrm{Na}$-citrate buffer ( $\mathrm{pH} 5.0)$ at $50^{\circ} \mathrm{C}$ for $10 \mathrm{~min}$. Enzyme activities are expressed as katals, and calculated as the ratio of released reducing sugars to incubation time. The concentration of reducing sugars was measured with 3,5-dinitrosalicylic acid reagent [28].

\section{Purification of endoglucanase}

Endoglucanases $T a C e l 5 \mathrm{~A}$ and $A f C e l 12 \mathrm{~A}$ were purified from supernatants of the 3-1 bioreactors. Culture broths were concentrated with Vivaflow 50 tangential crossflow concentrator (MWCO 10000 Da, Sartorius Stedim Biotech $\mathrm{GmbH}$, Germany). Concentrated supernatants were thoroughly washed with ultrapure water to remove residual salts remaining from the culture media, after which the water was exchanged to the equilibration buffer of the subsequent purification step. TaCel5A was loaded on a 5-ml DEAE purification column (GE Healthcare Bio-Sciences AB, Sweden) equilibrated with $20 \mathrm{mM}$ $\mathrm{Na}$-acetate buffer ( $\mathrm{pH}$ set to 5.0 ), and eluted by increasing the $\mathrm{NaCl}$-concentration from 0 to $0.15 \mathrm{M}$ linearly over 6 column volumes. Protein fractions eluting in $0.12-0.15 \mathrm{M}$ $\mathrm{NaCl}$ concentration were collected. AfCel12A was purified on a 5-ml SP-FF purification column (GE Healthcare BioSciences AB, Sweden) equilibrated with $20 \mathrm{mM} \mathrm{Na}$-citrate buffer ( $\mathrm{pH}$ set to 3.0), and eluted with a stepwise gradient increasing $\mathrm{NaCl}$ concentration from $0 \mathrm{M}$ to 0.10 and then further to $0.13 \mathrm{M}$. The protein fractions eluting in 0.10 $0.13 \mathrm{M} \mathrm{NaCl}$ concentration were collected. The enzyme solution was concentrated by ultrafiltration with $10 \mathrm{kDa}$ MWCO Vivaspin $20 \mathrm{ml}$ tubes (Sartorius Stedim Biotech $\mathrm{GmbH}$, Germany), and thoroughly washed with the equilibration buffer of the preceding purification step to remove $\mathrm{NaCl}$. Protein purity was verified using SDS-PAGE and estimated to be over $95 \%$ for both enzymes.

\section{Additional file}

Additional file 1: Supplementary figures, containing Figures S1-S4.

\section{Abbreviations}

AOX1: Alcohol oxidase I; EG: Endoglucanase; GAP: Glyceraldehyde-3phosphate dehydrogenase; GH: Glycoside hydrolase; OD: Optical density; PASC-FP: Phosphoric acid swollen cellulose from filter paper; SDS-PAGE: Sodium dodecyl sulfate polyacrylamide gel electrophoresis.

\section{Competing interests}

The authors declare no competing interest.

\section{Authors' contributions}

$A V, C T, G M$ and $V E$ designed and coordinated the work. AV, CT, OB, AA GM carried out the experiments. AV, CT, GM and VE wrote the manuscript. All authors participated in finalizing the manuscript and have read and approved the final manuscript.

\section{Acknowledgements}

This work was funded by the Framework Programme 7 (FP7) research project Waste2Go granted by the EU (Grant Agreement No.: 308363). We thank David Cannella and Bjørge Westereng for supplying PASC-FP.

\section{Author details}

'Department of Chemistry, Biotechnology and Food Science, Norwegian University of Life Sciences, PO Box 5003Chr. Magnus Falsens vei 1, N-1432 Ås, Norway. ${ }^{2}$ Centre for Process Innovation Limited, Wilton Centre, Wilton, Redcar TS10 4RF, UK.

Received: 27 December 2013 Accepted: 14 April 2014 Published: 18 April 2014

\section{References}

1. Menon V, Rao M: Trends in bioconversion of lignocellulose: biofuels, platform chemicals \& biorefinery concept. Prog Energy Combust Sci 2012, 38:522-550.

2. Horn SJ, Vaaje-Kolstad G, Westereng B, Eijsink VGH: Novel enzymes for the degradation of cellulose. Biotechnol Biofuels 2012, 5:45 
3. Mba Medie F, Davies GJ, Drancourt M, Henrissat B: Genome analyses highlight the different biological roles of cellulases. Nat Rev Microbiol 2012, 10:227-234.

4. Szijártó N, Horan E, Zhang J, Puranen T, Siika-aho M, Viikari L: Thermostable endoglucanases in the liquefaction of hydrothermally pretreated wheat straw. Biotechnol Biofuels 2011, 4:2.

5. Damasceno LM, Huang CJ, Batt CA: Protein secretion in Pichia pastoris and advances in protein production. Appl Microbiol Biotechnol 2012, 93:31-39.

6. Grinna LS, Tschopp JF: Size distribution and general structural features of $\mathrm{N}$-linked oligosaccharides from the methylotrophic yeast, Pichia pastoris. Yeast 1989, 5:107-115.

7. Cregg JM, Vedvick TS, Raschke WC: Recent advances in the expression of foreign genes in Pichia pastoris. Nat Biotechnol 1993, 11:905-910.

8. Mattanovich D, Graf A, Stadlmann J, Dragosits M, Redl A, Maurer M, Kleinheinz M, Sauer M, Altmann F, Gasser B: Genome, secretome and glucose transport highlight unique features of the protein production host Pichia pastoris. Microb Cell Fact 2009, 8:29.

9. Turan $Y$, Zheng M: Purification and characterization of an intracellular $\beta$-glucosidase from the methylotrophic yeast Pichia pastoris. Biochem Mosc 2005, 70:1363-1368.

10. Cereghino JL, Cregg JM: Heterologous protein expression in the methylotrophic yeast Pichia pastoris. FEMS Microbiol Rev 2000, 24:45-66.

11. Daly R, Hearn MTW: Expression of heterologous proteins in Pichia pastoris: a useful experimental tool in protein engineering and production. J Mol Recognit 2005, 18:119-138.

12. Zhang AL, Luo JX, Zhang TY, Pan YW, Tan YH, Fu CY, Tu FZ: Recent advances on the GAP promoter derived expression system of Pichia pastoris. Mol Biol Rep 2009, 36(6):1611-1619.

13. Ellis SB, Brust PF, Koutz PJ, Waters AF, Harpold MM, Gingeras TR: Isolation of alcohol oxidase and two other methanol regulatable genes from the yeast Pichia pastoris. Mol Cell Biol 1985, 5:1111-1121.

14. Waterham HR, Digan ME, Koutz PJ, Lair SV, Cregg JM: Isolation of the Pichia pastoris glyceraldehyde-3-phosphate dehydrogenase gene and regulation and use of its promoter. Gene 1997, 186:37-44.

15. Crowley JC, Kaback DB: Molecular cloning of chromosome I DNA from Saccharomyces cerevisiae: isolation of the ADE1 gene. J Bacteriol 1984, 159:413-417.

16. Lin Cereghino GP, Lin Cereghino J, Sungaa AJ, Johnson MA, Lim M, Gleeson MA, Cregg JM: New selectable marker/auxotrophic host strain combinations for molecular genetic manipulation of Pichia pastoris. Gene 2001, 263:159-169.

17. Kozak M: Point mutations define a sequence flanking the AUG initiator codon that modulates translation by eukaryotic ribosomes. Cell 1986, 44:283-292.

18. Bretthauer RK, Castellino FJ: Glycosylation of Pichia pastoris-derived proteins. Biotechnol Appl Biochem 1999, 30:193-200.

19. Stratton J, Chiruvolu V, Meagher M: High cell-density fermentation. In Methods in Molecular Biology. Volume 103: Pichia Protocols. Edited by Higgins DR, Cregg JM. Totowa, NJ: Humana Press Inc; 1998:107-120.

20. Mellitzer A, Weis R, Glieder A, Flicker K: Expression of lignocellulolytic enzymes in Pichia pastoris. Microb Cell Fact 2012, 11:61.

21. Tu FZ, Fu CY, Zhang TY, Luo JX, Zhang AL: Constitutive expression of human angiostatin in Pichia pastoris using glycerol as only carbon source. Chin J Biotechnol 2007, 23(5):902-906.

22. Tang S, Boehme L, Lam H, Zhang Z: Pichia pastoris fermentation for phytase production using crude glycerol from biodiesel production as the sole carbon source. Biochem Eng J 2009, 43:157-162.

23. Doring F, Klapper M, Theis S, Daniel H: Use of the glyceraldehyde-3phosphate dehydrogenase promoter for production of functional mammalian membrane transport proteins in the yeast Pichia pastoris. Biochem Biophys Res Commun 1998, 250:531-535.

24. Menéndez J, Hernández L, Banguela A, País J: Functional production and secretion of the Gluconoacetobacter diazatrophicus fructose-releasing exo-levanase (LsdB) in Pichia pastoris. Enz Microb Technol 2004, 34(5):446-452.

25. Yang B, Wyman CE: BSA treatment to enhance enzymatic hydrolysis of cellulose in lignin containing substrates. Biotechnol Bioeng 2006, 94(4):611-617

26. Heckman KL, Pease LR: Gene splicing and mutagenesis by PCR-driven overlap extension. Nat Protoc 2007, 2:924-932.
27. Invitrogen Corporation: PichiaPink ${ }^{\mathrm{TM}}$ expression system for high-level and largescale expression and secretion of bioactive recombinant proteins in Pichia pastoris. 2014. Publication Number MAN0000717. [http:/tools.lifetechnologies.com/ content/sfs/manuals/pichiapink_expression_system_man.pdf]

28. Miller $\mathrm{GL}$ : Use of dinitrosalicylic acid reagent for determination of reducing sugar. Anal Chem 1959, 31:426-428.

29. Ghose TK: Measurement of cellulase activities. Pure App/ Chem 1987, 59:257-268

doi:10.1186/1475-2859-13-57

Cite this article as: Várnai et al:: Expression of endoglucanases in Pichia pastoris under control of the GAP promoter. Microbial Cell Factories 2014 13:57.

\section{Submit your next manuscript to BioMed Central and take full advantage of:}

- Convenient online submission

- Thorough peer review

- No space constraints or color figure charges

- Immediate publication on acceptance

- Inclusion in PubMed, CAS, Scopus and Google Scholar

- Research which is freely available for redistribution 